\title{
Security over health: the effect of security policies on migrant mental health in the United Kingdom
}

\author{
Philipa Mladovsky
}

\section{Introduction: conflicts between security and health agendas}

The human right to health is, by definition, an inclusionary concept. Enshrined in the Human Rights Charter, it obliges nation states to ensure access to necessary preventive, promotive, and curative health resources irrespective of age, gender, social status, or migration history. Yet this concept is fundamentally at odds with migration policies, which are often exclusionary for forced migrants - concerned with determining the rights and responsibilities of certain individuals in contrast to others within the bounds of geopolitical nation states (Bozorgmehr and Jahn, 2019).

This clash of concepts can be observed in many countries when considering restrictions in access to healthcare services based on citizenship or legal status. Several countries in the European Union, for example, have foregone the right to health by providing only basic emergency care to undocumented migrants, or by charging asylum seekers and refugees high out-of-pocket payments to receive care (Abubakar et al., 2018).

However, the clash is evident not only in the health sector. The human right to health requires inter-sectoral action between multiple institutions, as social determinants such as employment, housing, or legal aspects can have powerful influences on the distribution of illness and access to care. For migrants, decisions and discourses on migration made in policy spaces traditionally considered outside of the health realm have been shown to have a significant impact on health outcomes (Juárez et al., 2019). It is thus important to consider not only the securitisation of health issues that lie within the responsibility of the health sector (see also Chapter 6 "Tensions between health security and universal health coverage in the context of forced migration”), but also the effects of security discourses in the broader policy space. Recently, the Global Compact on Safe, Orderly and Regular Migration has encountered criticism for prioritising security concerns and side-lining the human right to health (Bozorgmehr and Biddle, 2018). Yet the health effects of a shift of the political agenda towards security concerns have rarely been considered.

This chapter explores how the clash between security and health concerns has manifested through two case studies in the United Kingdom (UK) and considers the impact of security policies on the mental health of asylum seekers and refugees. The first case study is among asylum seekers in detention; while the second focuses on 
the asylum process and struggles for housing, employment, and access to health care experienced by forced migrants in their everyday lives. Using the UK as a pertinent example, this chapter finds evidence to support the argument that social policies targeting forced migrants not only fail to adequately treat mental health problems in forced migrants, but also seem to create mental health problems in this population by prioritising security concerns over health.

\section{Asylum seeker and refugee mental health in detention}

The first part of this case study concerns the treatment of mental health problems of migrants in detention centres. The UK is one of few countries that does not set a maximum time limit for holding asylum seekers in detention facilities and therefore holds people in these centres for longer than elsewhere in Europe (BMA, 2017). The UK also has one of the largest immigration detention estates in Europe, holding up to 3,500 individuals at any one time, in 11 immigration removal centres (IRCs) across the country. Decisions to detain are made by the Home Office, and until very recently were not subject to automatic review by a court or other independent body (the Immigration Act 2016 brought in automatic bail hearings at the four month point). Individuals rarely know the term of their detention, meaning that immigration detention is often referred to as "indefinite" or "indeterminate" (BMA, 2017).

Yet it is widely accepted that detention significantly negatively affects the mental health of asylum seekers; and the longer the length of time held in detention, the greater the deterioration (Priebe et al., 2016). International and UK evidence points to damaging effects of detention on asylum seekers' health, increasing the risk of conditions such as PTSD, anxiety, depression, and suicidal ideation, as well as suicide, with the negative effect of detention enduring long after release (BMA, 2017, Priebe et al., 2016, von Werthern et al., 2018, Shaw, 2016).

In 2010, the UK Border Agency changed the wording of its policy on detaining people with mental health problems, reversing the presumption against detaining mentally ill people. The previous policy provided that the mentally ill would "normally be considered suitable for detention in only very exceptional circumstances". The exclusion was amended to state: "those suffering from serious mental illness which cannot be satisfactorily managed within detention”. The Secretary of State did not consult on this change of wording, nor did she undertake an equality impact assessment. There were successful legal challenges to this policy in the two years following its introduction, but the policy was not changed as a result (RCP, 2013). As such, asylum seekers are treated for mental health conditions in parallel services in detention, provided separately from community services. These mental health services are co-commissioned by the National Health Service (NHS), the Home Office and Public Health England. 
The rationale for treating mental illness in detention is founded on security concerns. This was explained by Theresa May in 2015 when she was Home Secretary and commissioned an independent review into the Home Office policies and operating procedures that have an impact on immigration detainee welfare: "Immigration detention plays a key role in helping to secure our borders and in maintaining effective immigration control. The Government believes that those with no right to be in the UK should return to their home country and we will help those who wish to leave voluntarily. However, when people refuse to do so, we will seek to enforce their removal, which may involve detaining people for a period of time. But the wellbeing of those in our care is always a high priority and we are committed to treating all detainees with dignity and respect. I want to ensure that the health and wellbeing of all those detained is safeguarded." (Shaw, 2016)

In her statement, the health and wellbeing of detainees is presented as a factor that needs to be traded off against the priority of national security. However, given the ongoing long period of chronic underinvestment into wider mental health in the NHS in England (Mental Health Taskforce, 2016) (see below for further details), it is conceivable that the government's policy of safeguarding the health and wellbeing of detainees by providing parallel mental health services to migrants in detention could have resulted in relatively good access to care for this population.

The opposite appears to be true. The review commissioned by Theresa May, conducted by the former Prisons and Probation Ombudsman for England and Wales (Shaw, 2016), in addition to other reports commissioned by the Home Office (Shaw, 2018, Lawlor et al., 2015) and the NHS (Durcan et al., 2017), as well as reports by the HM Chief Inspector of Prisons, all point to poor conditions in detention which lead to increased mental ill health among detainees, as well as poor quality mental health care in these settings.

For example, Shaw (2016) found that: "Detention worsened mental health because it diminished the sense of safety and freedom from harm, it was a painful reminder of past traumatic experiences, it aggravated fear of imminent return, it separated people from their support networks and it disrupted their treatment and care". In particular he found that "most victims of torture experienced retraumatisation, including powerful intrusive recall of torture experiences and a deterioration of pre-existing trauma symptoms".

In terms of quality of care in detention, the review noted: poor mental health screening; the use of segregation (i.e. isolation) as the default location for those with serious mental health problems; insufficient provision of psychiatric care; and a lack of equivalence with mainstream community care, for example due to the scarcity of cognitive-behavioural therapies in detention.

The various reports written over successive years all have similar findings, suggesting little has changed, although some tentative improvements were recently noted. For example, in a follow-up to his 2016 report, Shaw (2018) welcomes the Adults at Risk (AAR) policy that was introduced by the Home Office in response to his proposals to reduce the numbers of vulnerable people in detention, but states that "while it is not clear that AAR has yet made a significant difference to those 
numbers, it has engendered a genuine focus on vulnerability. The policy remains a work in progress and I have made recommendations to strengthen the protections it offers".

An interesting, but difficult, question considered in the wider health and securitisation literature is whether the prioritisations of security issues over health issues actually increases UK security. In the UK, in practice, most detainees are not deported, suggesting they were never a threat to security in the first place. Of the 14,062 asylum seekers who left detention during 2017, about a quarter $(3,171)$ were actually removed from the UK when they left detention. 8,462 were granted temporary admission or released and a further 2,222 were released as a result of bail applications (Refugee Council, 2018). Shaw finds that the argument justifying the provision of mental health services in detention as protective of national security is probably incoherent and erroneous, as "evidence on compliance levels for alternative to detention programmes finds that well-funded, and well-supported case-management programmes offering legal advice, housing and access to social and health care have high levels of compliance with all stages of the immigration system, including removal.” (Shaw, 2018)

The findings outlined above suggest that in the UK, many asylum seekers are unnecessarily detained and that many of them are eventually returned into the community with untreated, poorly treated, and/or exacerbated levels of mental ill health. The suggested causal link between detention and worsening of mental health in the UK is consistent with a limited number of international longitudinal studies and comparison studies which find that detention not only exacerbates existing mental health disorders, but also contributes independently to the onset of new ones, although isolating the effects of detention alone remains a complex task (von Werthern et al., 2018). This is likely to create a greater burden of disease for mainstream community-based mental health services. As such, the prioritisation of security issues over migrant mental health in detention seems to promote inequitable, poor quality and inefficient care. However, ineffective policies and practices are not only found in the context of detention. Next, this case study turns to the problems caused by further prioritisation of security over mental illness among forced migrants in the UK, in their everyday lives.

\section{Security and mental health in the everyday lives of asylum seekers and refugees}

The anthropological analysis of securitisation (Samimian-Darash and Stalcup, 2017) has deconstructed the "securitisation" debate (see also Chapter 6 "Tensions between health security and universal health coverage in the context of forced migration"), proposing an analysis of "security assemblages" to understand how security concerns manifest in the everyday lives of individuals. Security assemblages do not necessarily focus on security formations (such as detention 
centres) per se, and how much violence or insecurity they yield, but rather seek to identify and study security forms of action, whether or not they are part of the nation-state. This approach is oriented toward capturing how these forms of action work and what types of security they produce. This means everyday forms of action outside official security formations can be analysed through a security lens.

Immigration policies and debates have been analysed as one such assemblage. In the UK, as in the EU more broadly, immigration is framed by some politicians and parts of the media and population as a threat to security. Forced and other types of migrants are seen not only as a threat to national internal security due to fears of terrorism (Huysmans and Buonfino, 2008), but also as a threat to the supposed societal security conferred by a homogenous national communal identity, and to economic security by supposedly creating a strain on employment and social welfare (Huysmans, 2006).

In the UK, everyday forms of security action designed to deter immigration take place in the context of what until recently was officially termed by the government as the "hostile environment" policy (as a result of widespread criticism, since the summer of 2017 the government has used the term "compliant environment" instead) (Taylor, 2018). The "hostile environment" policy refers to a range of government measures aimed at identifying and reducing the number of immigrants in the UK with no right to remain, including so-called "failed asylum seekers". An overview of the policy has been set out by the House of Commons Home Affairs Committee, which stated: "Many of the measures designed to make life difficult for individuals without permission to remain in the UK were first proposed in 2012 as part of a 'hostile environment policy'. The aim of the policy is to deter people without permission from entering the UK and to encourage those already here to leave voluntarily. It includes measures to limit access to work, housing, healthcare, and bank accounts, to revoke driving licences and to reduce and restrict rights of appeal against Home Office decisions. The majority of these proposals became law via the Immigration Act 2014, and have since been tightened or expanded under the Immigration Act 2016” (House of Commons Home Affairs Committee, 2018)

This policy has led to increased security concerns in many aspects of everyday life, both for migrants and the majority population. In the job market and housing, for example, employers and landlords are put in the position of internal border guards in order to police the implementation of immigration policies and detect undocumented migrants (Yuval-Davis, 2018). These policies accompany measures within the asylum system that also seek to deter asylum seekers by keeping access to employment and social welfare low. For example, compared to Spain, France and Germany, Britain provides less financial support for asylum seekers to cover nonaccommodation related expenses. Compared to these three countries and Italy, the UK has the strictest restrictions on asylum seekers working as they are not allowed into paid employment unless they have been waiting to hear about their asylum claim for 12 months, and then they are only allowed to work in official "shortage occupations" for which there are not enough resident workers to fill vacancies (The Guardian, 2017). Furthermore, 28 days after being granted refugee status, people 
stop receiving government support as an asylum seeker and must apply to receive mainstream benefits if needed, as stated in regulation 4 of the Asylum Support Regulations 2002. Although people granted status should have immediate access to the labour market and all key mainstream benefits, this transition can prove problematic and will often take longer than the prescribed 28 days. The last Labour government (1997 - 2010) provided support and advice to new refugees, so that they were better able to transition into mainstream society, funding both voluntary and local authority agencies to provide a package of support. However, this funding was cut in 2011 by the coalition government that came into power in 2010 (Carnet et al., 2014). Very few refugees are able to register for benefits in the 28-day period due to bureaucratic and administrative delays and as a result, many become destitute or homeless (Smith, 2019, Basedow and Doyle, 2016, Carnet et al., 2014).

This process of securitisation, in which the government seeks to deter refugees and undocumented migrants through restricting their access to housing, employment and health care, as well as prolonging and complicating the asylum process, has led to an increased risk of mental ill health in forced migrants. This is evidenced by a literature review on the impact of policies of deterrence on the mental health of asylum seekers in the UK and elsewhere (Silove et al., 2000). Deterrence measures covered by the study include confinement in detention centres, enforced dispersal within the community, the implementation of more stringent refugee determination procedures, and temporary forms of asylum. Additionally, in several countries including the UK, asylum seekers living in the community face restricted access to work, education, housing, welfare, and/ or basic health care services. Allegations of abuse, untreated medical and psychiatric illnesses, suicidal behaviour, hunger strikes, and outbreaks of violence among asylum seekers in detention centres are reported. The study finds that despite methodological limitations due to sampling difficulties, there is growing evidence that salient postmigration stress facing asylum seekers adds to the effect of previous trauma in creating risk of ongoing posttraumatic stress disorder and other psychiatric symptoms. Indeed, an international review of the literature observed that adverse post-migratory socioeconomic conditions accounted for the larger burden of depression in settled refugees ( $>5$ years) when compared to the host populations. The effect was not observed in refugees settled in the host country for less than 5 years (Priebe et al., 2016). This case study of the UK serves as an example of how such increases in mental ill health among refugees are actively shaped by policies of deterrence stemming from a process of securitisation.

In an example from the UK, a study of 84 Iraqi asylum seekers reports that low levels of social support and financial difficulties after migration were associated with heightened levels of depression (Gorst-Unsworth and Goldenberg, 1998). In another study in which 138 refugees and asylum seekers were interviewed (Phillimore et al., 2007), the following post-migratory factors were reported by the interviewees to negatively impact their mental health: the length of time it took for an asylum decision to be reached; questioning of stories which were difficult to tell; uncertainty about the future; being detained; being criminalised, stigmatisation and 
respondents developing a mistrust of the state; discrimination, feeling unwelcome and being harassed or bullied; isolation, loss or separation from friends and family and ethnic community; unemployment and skills downgrading, concerns around inability to be self-sufficient; culture shock and difficulties understanding how to conduct themselves in UK society; difficulties accessing services, in particular housing; gender issues including isolation from traditional child rearing and social support networks, sexual and domestic violence, increased difficulties accessing services, English language classes and work, and the belief by some that women are inherently weak. Many, although not all, of these factors can be understood as policies of deterrence.

Another example comes from the housing sector. Individuals seeking asylum in the UK, and who can prove they are destitute, are eligible for support from the Home Office. Support can be financial and in the form of accommodation. However, a report by the House of Commons home affairs select committee (2017) highlighted that many properties in which asylum seekers were housed were characterised by substandard, unsanitary or unsafe conditions, such as vermin infestation, and pointed to the failures of the inspection and compliance regimes to deal with these issues. Aside from the well-known negative effects poor housing has on mental health (Diggle, 2017) the report found specific conditions of the housing provided to be especially detrimental. Perhaps most notably, forced migrants were moved between housing facilities frequently and at very short notice, which often affected support networks, including losing vital access to Community Mental Health Team care as a result of the lack of effective onward referral.

A deterrence policy that has caused particular concern is the loss of asylum social welfare support for asylum seekers 28 days after they are granted status. The Refugee Council has documented the negative impact these cuts have had on the living conditions and mental health of refugees (Basedow and Doyle, 2016). The report draws on interviews conducted with 11 newly recognised refugees who were interviewed up to four times during the period after they had been granted status. The study found that all participants reported stress, anxiety, and depression (both clinically diagnosed and self-described) during their interviews. The initial 28 day "move on" period was the most stressful for participants and the highest levels of anxiety were reported during this time.

Understanding the impact of specific post-migratory policies on the mental health of migrants can be difficult, however, as causes are likely to be multifactorial and cause and effect are often bi-directional. A study of refugees drawing on the Labour Force Survey in the UK illustrates this difficulty (Ruiz and Vargas - Silva, 2018). The study finds those who migrated to seek asylum have worse labour market outcomes than natives and other types of migrants, including a lower likelihood of employment, lower weekly earnings, lower hourly salary, and lower number of hours worked. The study also finds that asylum seekers have worse mental health, but the authors are unable to determine the casual links between the two variables. The authors hypothesise that poor mental health (in the form of premigration trauma) may be a cause of lower employment, rather than vice versa. 
Indeed, the relationship between unemployment and ill-health may work in both directions (Paul and Moser, 2009). Another possible explanation they provide for their findings is evidence that refugee skills may be less readily transferable across countries than those of other migrants and that differences in the main motivation to migrate suggest that refugees may be less favourably selected for labour market success in the host country. They also consider the effect of policies of deterrence (i.e. lengthy legal restrictions to access the labour market while asylum claims are being evaluated) on refugee employment levels but recognise that these are unlikely to be the sole explanation.

It is difficult to determine exactly how and why policies of deterrence impact mental health. Meta-analytic evidence from international cross-sectional and longitudinal studies that demonstrate the negative effect of unemployment on mental health in general populations are unable to identify the specific mechanisms that mediate this association (Paul and Moser, 2009). Qualitative research such as Phillimore's study of refugees (2007) is also limited in terms of providing robust evidence on causality, as it often relies on respondents' self-reports which may be unable to reliably unpack and explain causal chains.

Turning to the issue of whether deterrence policies are in fact an effective means of enhancing security, it seems this is difficult to assess in the UK. The UK's Independent Chief Inspector of Borders and Immigration has stated that "the Home Office does not have in place measurements to evaluate the effectiveness" of the "hostile environment provisions" (House of Commons Home Affairs Committee, 2018).

Ostensibly, policies of deterrence may have been effective in reducing applications of asylum to the UK, which have decreased rapidly over recent years. Asylum applications declined sharply during the mid-2000s, compared to the peak in the early 2000s. They increased again from 2010 to 2015 (though well below the levels of the early 2000s), but have decreased again in 2016 and 2017 (The Migration Observatory, 2019). However, this is unlikely to be the cause of deterrence policies, as the causes of changes in asylum applications are complex and determined by multiple factors. Indeed, evidence from across the OECD suggests that rather than policies of deterrence, it is structural factors that largely lie beyond the reach of asylum policy makers, such as a country's prosperity, the unemployment rate and historical ties, that determine asylum seekers' choice of host country (THIELEMANN, 2004, THIELEMANN, 2003). It is also unlikely that the decrease in asylum seeking claims has in turn increased security in any sense of the word in the UK, as there is little evidence to suggest asylum seekers are in fact a threat to security (Innes, 2010, United Nations General Assembly, 2016).

However, regardless of the possible effects on security, what can be argued with confidence is that forced migrants are likely to have a relatively high level of need for mental health services compared to the majority population, given their past exposure to traumatic experiences and on ongoing stressors, and these needs are very likely be exacerbated by their experiences in detention and by policies of 
deterrence such as the "hostile environment". The next section looks in more depth at mental health services that are offered to forced migrants in the community.

\section{Inadequate mental health services for forced migrants}

To what extent does the government in the UK provide or fund mental health services for forced migrants? In terms of eligibility, asylum seekers with an ongoing claim and refugees are entitled to the full range of NHS services. However, undocumented migrants and refused asylum seekers are charged for using the NHS, except for: emergency care; discretionary acceptance by a GP to enrol in the primary care practice; some specific services (infectious diseases, family planning, treatment of a physical or mental condition caused by torture, female genital mutilation, domestic violence, or sexual violence). As discussed above, some health care is also provided in detention.

Since 2015, as part of the "hostile environment" policy, fees charged for (nonemergency) secondary care to undocumented migrants increased to $150 \%$ of the actual cost. Hospitals are fined if fees are not recouped - they must therefore check patients' immigration status and chase the fee. Any immigration application from a person with more than $£ 1000$ debt for NHS services is automatically rejected.

These policies alone already severely limit access to needed health services, including mental health, for many forced migrants. However, under the "hostile environment" policy, the NHS has also been required to act as a form of border control, adding a further barrier to access. In the last few years the Home Office gained permission to request non-clinical details from NHS Digital, including patients' names, dates of birth, and the individual's last known address. According to the Department of Health, the Home Office made 8,127 requests for data in the first 11 months of 2016, which led to 5,854 people being traced by immigration enforcement teams. Public Health England (PHE) warned that the sharing of personal information by NHS commissioners and healthcare providers risks undermining public confidence in the NHS and could have "unintended serious consequences" for patients. However, the Department of Health denied such claims, saying it had found "no evidence that this policy would deter migrants from seeking treatment," adding that it had weighed up privacy considerations and the "competing public interest in upholding the Government's immigration agenda". Fortunately, this damaging policy was recently officially overturned as a result of lobbying from multiple NGOs and stakeholders, but may still be ongoing in practice (Independent, 2019).

In addition to these eligibility and privacy barriers, there is a general lack of provision of specialised mental health services for forced migrants. For example, a study found highly variable provision of mental health services for asylum seekers and refugees in London (Ward and Palmer, 2005) only five of the eleven Mental Health Trusts provide specialist services that are specifically designed with the 
needs of refugees and asylum seekers in mind. Some services provided by the other Trusts provide specialist trauma services for refugees and asylum seekers (who make up about $50 \%$ of their client group), but do not have a team or an individual that works specifically with/ specialises on asylum seekers and refugees.

Guidance on improving and commissioning mental health care for migrants in England is provided by the NGO MIND (Fassil and Burnett, 2014, MIND, 2009a, MIND, 2009b, MIND, 2017). MIND points to some cases of best practice, but overall their reports suggest that mental health service provision for migrants in the community is inadequate and relies heavily on poorly funded voluntary organisations. They find that migrants' needs are not prioritised, in part due to a lack of understanding among these communities about how the health system works, including difficulties registering with GP practices. Even if migrants have accessible and supportive GPs, mental health services are spread very thinly, creating long waiting times for resource-poor services and therapies. MIND also finds the stigma and taboo associated with mental illness can be harder to overcome in migrant populations, where cultural beliefs may perpetuate stereotypes and make it hard for families and communities to accept mental health problems. These problems accessing mental health services among forced migrants reflect the wider barriers to health care experienced by this population group in general (Mladovsky et al., 2012).

It is important to note that problems accessing mental health services among forced migrants in the UK also often reflects wider inequities in quality of mental health care experienced by black, Asian, and minority ethnic (BAME) groups. In the UK, there are wide ethnic inequalities in access to mental health services. Research over 50 years shows people from BAME backgrounds have worse mental health care access and outcomes compared to the majority UK population: they are over-represented in inpatient/psychiatric care and sectioned more often; and underrepresented in talking therapy (Joint Commissioning Panel for Mental Health, 2014). Race equality legislation and policies to address discrimination have been introduced over last several years but racial discrimination remains an ongoing problem in the NHS. The Joint Commissioning Panel for Mental Health (2014) states this inequity is due to "socioeconomic factors, racism and discrimination".

It is, however, difficult to generate robust evidence on inequities in access to mental health services among forced migrants in the UK, as the necessary data are rarely collected. The exact number of refugees living in local authority areas and their health status is generally unknown; and no routine information is collected at local authority level on the number of refused asylum seekers who remain in the UK or undocumented/ illegal migrants and of their health status (Aspinall, 2014).

In the UK there is no recording of asylum seeker, refugee, migrant/country of birth or migrant subgroups data in Hospital Episode Statistics Datasets. The NHS Central (GP) Register only flags individuals where the previous address is outside the UK and the person enters England \& Wales for the first time and registers with a GP, but not asylum or refugee specific data. By contrast, the Referral Route indicator in the Mental Health Minimum Data Set does include 'Asylum Services' 
and the Child and Adolescent Mental Health Services (CAMHS) Dataset has citizenship status and country of birth fields.

The lack of data means that an evidence base is lacking for the development of policy in the UK. For example, the Mental health: migrant health guide published by Public Health England (2017) contains advice and guidance on the health needs of migrant patients for healthcare practitioners, including refugees and asylum seekers. However, it mostly draws on international evidence from WHO and UNHCR, not evidence from the UK. Similarly, the National Institute for Health and Care Excellence (NICE) guidelines for the treatment of PTSD (2005) guidelines concerning refugees are based on samples of adult refugees from Kosovo in the UK, Cambodian adult refugees on the Thai border, Bosnian refugees living in Croatia, a community sample of Vietnamese adults in Australia, war-affected Tamil refugees and immigrants in Australia, tortured and non-tortured Bhutanese refugees living in Nepal and community samples in Algeria, Cambodia, Ethiopia, and Gaza. In the NICE (2009) guidelines for treatment of depression, ethnicity is discussed but there is no mention of asylum seekers or refugees at all.

Overall, then, the provision of mental health services to forced migrants in the community appears to be inadequate, data collection on this issue is poor, and the data that are available often do not seem to be used to inform policy. This situation is likely to be detrimental not only to forced migrants themselves, but may also harm wider community relations, as poor mental health among forced migrants may hinder their successful integration (Phillimore, 2011). Poor migrant integration in turn undermines the government's own security concerns, as successive governments in the UK over the last 20 years have portrayed poor migrant integration as a security threat, although the extent to which this is in fact the case is debatable (Garbaye and Latour, 2016).

\section{Bridging the gap between security and health concerns}

This chapter describes the contradictory nature of security concerns based on exclusionary principles and the right to health, which is inclusive. It also discusses how policy discourses have shifted in recent years towards security concerns, in terms of detaining mentally ill asylum seekers, providing mental health services in detention, and creating mental health problems in forced migrants through a process of securitisation of the wider asylum and immigration system. The prioritisation of security concerns has therefore increasingly led to a neglect of asylum seekers' right to health.

The UK case study highlights the mechanisms by which the mental health of forced migrants is created and exacerbated by policies intended to prioritise security concerns, both worsening the mental health status for these persons and further impeding access to necessary mental health services. The securitisation of migrant livelihoods through prolonged detention and deterrence measures, such as the 
difficult access of welfare benefits, employment, and education, exacerbate mental health problems by creating a lack of socio-economic security, withdrawing social support networks and increasing discrimination (see also Chapter 10 "Discrimination as a health systems response to forced migration"). At the same time, access to required mental health services is impeded through a number of securitising measures: through an active restriction of entitlements and increase in co-payments, by encouraging the "policing" of irregular migration in healthcare encounters and by failing to provide services which adequately cater to the needs of forced migrants (see also Chapter 11 "Health systems responsiveness to the mental health needs of forcibly displaced persons").

Ironically, this prioritisation of security issues seems to have provided neither health benefits nor benefits to security, whether national, economic, political, community, or individual. In the case of forced migrant mental health, however, according to the governments' own logic, securitisation may potentially ironically lead to greater insecurity, due to the poor social integration that may result from increased rates of forced migrant mental ill health.

The system is in need of major reform. The inter-sectoral approach enshrined in the right to health works both ways: not only can health be improved by adopting a human rights-based approach during the asylum process. The health of a society, safeguarded by an inclusionary right to health approach, can also function as a resource enhancing the security of the nation state. Thus there is a need to cease to detain mentally ill asylum seekers; improve service provision to this population in the community; and adopt a more humane asylum system that does not actively create mental health problems, for example by increasing access to work, housing, and health care. 


\section{References}

ABUBAKAR, I., ALDRIDGE, R. W., DEVAKUMAR, D., ORCUTT, M., BURNS, R., BARRETO, M. L., DHAVAN, P., FOUAD, F. M., GROCE, N. \& GUO, Y. 2018. The UCL-Lancet Commission on Migration and Health: the health of a world on the move. The Lancet, 392, 2606-2654.

ASPINALL, P. J. 2014. Hidden Needs. Identifying Key Vulnerable Groups in Data Collections: Vulnerable Migrants, Gypsies and Travellers, Homeless People, and Sex Workers. https://assets.publishing.service.gov.uk/government/uploads/system/uplo ads/attachment_data/file/287805/vulnerable_groups_data_collections.pd $f$ Centre for Health Services Studies, University of Kent.

BASEDOW, J. \& DOYLE, L. 2016. England's forgotten refugees: Out of the fire and into the frying pan, Refugee Council. https://www.refugeecouncil.org.uk/wpcontent/uploads/2019/03/England_s_Forgotten_Refugees_final.pdf.

BMA 2017. Locked up, locked out: health and human rights in immigration detention. A report by the British Medical Association London.

BOZORGMEHR, K. \& BIDDLE, L. 2018. New UN compact for migration falls short on health. British Medical Journal, k5327.

BOZORGMEHR, K. \& JAHN, R. 2019. Adverse health effects of restrictive migration policies: building the evidence base to change practice. The Lancet Global Health, 7, e386-e387.

CARNET, P., BLANCHARD, C. \& APOLLONIO, F. 2014. The move-on period: an ordeal for new refugees, London, British Red Cross.

DIGGLE, J., BUTLER, H., MUSGROVE, M. AND WARD, R. 2017. Brick by brick: A review of mental health and housing, London, Mind.

DURCAN, G., STUBBS, J. \& BOARDMAN, J. 2017. Immigration Removal Centres in England. A mental health needs analysis, London, Centre for Mental Health.

FASSIL, Y. \& BURNETT, A. 2014. Commissioning mental health services for vulnerable adult migrants. Guidance for commissioners, https://www.mind.org.uk/media/1380137/Vulnerable-Migrants-guidancefor-commissioners-August-2014-FINAL.pdf, MIND.

GARBAYE, R. \& LATOUR, V. 2016. Community and Citizenship in the Age of Security: British Policy Discourse on Diversity and Counter-terrorism since 9/11 Revue Française de Civilisation Britannique, XXI.

GORST-UNSWORTH, C. \& GOLDENBERG, E. 1998. Psychological sequelae of torture and organised violence suffered by refugees from Iraq. Traumarelated factors compared with social factors in exile. Br J Psychiatry, 172, 90-4.

HOUSE OF COMMONS HOME AFFAIRS COMMITTEE 2018. Immigration Policy: Basis for Building Consensus, 15 January 2018, HC 500 of session 2017-19, p 20. 
HOUSE OF COMMONS HOME AFFAIRS SELECT COMMITTEE 2017. Asylum accomodation. https://publications.parliament.uk/pa/cm201617/cmselect/cmhaff/637/63 702.htm.

HUYSMANS, J. 2006. The politics of insecurity : fear, migration and asylum in the $E U$, London, Routledge.

HUYSMANS, J. \& BUONFINO, A. 2008. Politics of Exception and Unease: Immigration, Asylum and Terrorism in Parliamentary Debates in the UK. Political Studies 56, 766-788.

INDEPENDENT 2019. Home Office still using NHS patient data for immigration enforcement despite suggesting it would end practice. https://www.independent.co.uk/news/uk/home-news/home-office-nhsdata-sharing-immigration-enforcement-a8761396.html.

INNES, A. J. 2010. When the Threatened Become the Threat: The Construction of Asylum Seekers in British Media Narratives. International Relations, 24, 456-477.

JOINT COMMISSIONING PANEL FOR MENTAL HEALTH 2014. Guidance for commissioners of mental health services for people from black and minority ethnic communities. https:/www.jcpmh.info/wpcontent/uploads/jcpmh-bme-guide.pdf

JUÁREZ, S. P., HONKANIEMI, H., DUNLAVY, A. C., ALDRIDGE, R. W., BARRETO, M. L., KATIKIREDDI, S. V. \& ROSTILA, M. 2019. Effects of non-health-targeted policies on migrant health: a systematic review and meta-analysis. The Lancet Global Health, 7, e420-e435.

LAWLOR, D., SHER, M. \& STATEVA, M. 2015. Review of Mental Health Issues in Immigration Removal Centres. Immigration \& Border Policy Directorate, The Home Office.

MENTAL HEALTH TASKFORCE 2016. The five year forward view for mental health, Mental Health Taskforce to the NHS in England.

MIND 2009a. A civilised society. Mental health provision for refugees and asylumseekers in England and Wales, London, Mind.

MIND 2009b. Improving mental health support for refugee communities - an advocacy approach. https://www.mind.org.uk/media/192447/Refugee_Report_1.pdf.

MIND 2017. Mental health commissioning with migrant communities. A guide for mental health service providers. https://www.mind.org.uk/media/14259589/mental-health-commissioningwith-migrant-communities.pdf.

MLADOVSKY, P., INGLEBY, D., MCKEE, M. \& RECHEL, B. 2012. Good practices in migrant health: the European experience. Clin Med, 12, 24852.

NICE 2005. Post-traumatic stress disorder: management. Clinical guideline [CG26]. https://www.nice.org.uk/guidance/cg26.

NICE 2009. Depression in adults: recognition and management. Clinical guideline. https://www.nice.org.uk/guidance/cg90/resources/depression-in-adultsrecognition-and-management-pdf-975742638037. 
PAUL, K. I. \& MOSER, K. 2009. Unemployment impairs mental health: Metaanalyses Journal of Vocational Behavior,, 74, 264-282.

PHILLIMORE, J. 2011. Refugees, Acculturation Strategies, Stress and Integration. Journal of Social Policy, 40, 575-593.

PHILLIMORE, J., ERGUN, E., GOODSON, L. \& HENNESSY, D. 2007. They do not Understand the Problem I Have: Refugee Well-being and Mental Health, York, Joseph Rowntree Foundation.

PRIEBE, S., GIACCO, D. \& EL-NAGIB, R. 2016. Public health aspects of mental health among migrants and refugees: a review of the evidence on mental health care for refugees, asylum seekers and irregular migrants in the WHO European Region, Copenhagen, WHO Regional Office for Europe; 2016 (Health Evidence Network (HEN) Synthesis Report 47).

PUBLIC HEALTH ENGLAND 2017. Mental health: migrant health guide. https://www.gov.uk/guidance/mental-health-migrant-healthguide\#history.

RCP 2013. Position Statement on detention of people with mental disorders in immigration removal centres. http://www.medicaljustice.org.uk/wpcontent/uploads/2016/06/Appendix-A-The-Royal-College-of-

Psychiatrists-Position-Statement-on-detention-of-people-with-mental-

disorders-in-Immigration-Removal-Centres.pdf, The Royal College of Psychiatrists.

REFUGEE COUNCIL 2018. Refugee Council Information. When is detention used?, Refugee Council. https://www.refugeecouncil.org.uk/wpcontent/uploads/2019/03/Detention_in_the_Asylum_System_May_2018. pdf

RUIZ, I. \& VARGAS - SILVA, C. 2018. Differences in labour market outcomes between natives, refugees and other migrants in the UK. Journal of Economic Geography, 18, 855-885.

SAMIMIAN-DARASH, L. \& STALCUP, M. 2017. Anthropology of security and security in anthropology: Cases of counterterrorism in the United States. Anthropological Theory, 17, 60-87.

SHAW, S. 2016. Review into the Welfare in Detention of Vulnerable Persons: A Report to the Home Office by Stephen Shaw, London, HMSO, CM 9186.

SHAW, S. 2018. Assessment of government progress in implementing the report on the welfare in detention of vulnerable persons, London, HMSO, CM 9661.

SILOVE, D., STEEL, Z. \& WATTERS, C. 2000. Policies of deterrence and the mental health of asylum seekers. JAMA, 284, 604-11.

SMITH, L. 2019. MIND THE GAP ONE YEAR ON. Continuation report on homelessness amongst newly recognised refugees, The No Accomodation Network. https://naccom.org.uk/wp-content/uploads/2019/06/NACCOMHomelessnesss-Report_2019-06-18_DIGITAL.pdf.

TAYLOR, R. 2018. House of Lords Library Briefing. 'Hostile Environment' Policy London.

THE GUARDIAN 2017. Britain is one of worst places in western Europe for asylum seekers. https://www.theguardian.com/uk- 
news/2017/mar/01/britain-one-of-worst-places-western-europe-asylumseekers.

THE MIGRATION OBSERVATORY 2019. Migration to the UK: Asylum and Refugees.

https://migrationobservatory.ox.ac.uk/resources/briefings/migration-tothe-uk-asylum/.

THIELEMANN, E. R. 2003. Does Policy Matter? On Governments' Attempts to Control Unwanted Migration., LSE European Institute Working Paper No. 2003-2, $<$ http://www.lse.ac.uk/collections/europeanInstitute/workingpaperindex.h tm>.

THIELEMANN, E. R. 2004. Why Asylum Policy Harmonisation Undermines Refugee Burden-Sharing. European Journal of Migration and Law, 6, 4765.

UNITED NATIONS GENERAL ASSEMBLY 2016. Report of the Special Rapporteur on the promotion and protection of human rights and fundamental freedoms while countering terrorism, https://documents-ddsny.un.org/doc/UNDOC/GEN/N16/285/61/PDF/N1628561.pdf?OpenEle ment.

VON WERTHERN, M., ROBJANT, K., CHUI, Z., SCHON, R., OTTISOVA, L., MASON, C. \& KATONA, C. 2018. The impact of immigration detention on mental health: a systematic review. BMC Psychiatry, 18, 382.

WARD, K. \& PALMER, D. 2005. Mapping the provision of mental health services for asylum seekers and refugees in London: a report. . ICAR. https://lemosandcrane.co.uk/resources/ICAR\%20\%20Mapping\%20the\%20provision\%20of\%20mental\%20health\%20servi ces\%20for\%20asylum\%20seekers\%20and\%20refugees\%20in\%20Londo n.pdf.

YUVAL-DAVIS, N., WEMYSS, G. AND CASSIDY, K., 2018. Everyday bordering, belonging and the reorientation of British immigration legislation. Sociology, 52, 228-244. 